TITLE:

\title{
Effects of ion-exchange treatment on bromate formation and oxidation efficiency during ozonation
}

\author{
$\operatorname{AUTHOR}(\mathrm{S})$ :
}

Echigo, S.; Itoh, S.; Niwa, A.

\section{CITATION:}

Echigo, S.... [et al]. Effects of ion-exchange treatment on bromate formation and oxidation efficiency during ozonation. Water Science \& Technology: Water Supply 2012, 12(2): 187 192

ISSUE DATE:

2012-03

URL:

http://hdl.handle.net/2433/174336

\section{RIGHT:}

(c) IWA Publishing 2012. The definitive peer-reviewed and edited version of this article is published in 'Water Science and Technology: Water Supply. Vol:12 No:2 pp:187-192 doi:10.2166/ws.2012.018' and is available at

www.iwapublishing.com.; This is not the published version. Please cite only the published version.; この論文は出版社版 でありません。引用の際には出版社版をご確認ご利用ください。 


\title{
Effects of Ion-Exchange Treatment on Bromate Formation and Oxidation Efficiency during Ozonation
}

\author{
S. Echigo*, S. Itoh* and A. Niwa** \\ * Graduate School of Global Environmental Studies, Kyoto University, C1, Nishikyo, Kyoto 65-8540, Japan \\ (E-mail:echigo@urban.env.kyoto-u.ac.jp; itoh@urban.env.kyoto-u.ac.jp) \\ ** Shimazu Corp., Nishinokyo-Kuwabara-cho, Nakagyo-ku, Kyoto 604-8511, Japan \\ (E-mail: a.niwa@shimadzu.co.jp)
}

\begin{abstract}
Ion-exchange treatment is a promising technique for removing hydrophilic compounds during drinking water treatment. In this study, we applied several different ion exchangers (i.e., anion exchange resins and a hydrotalcite compound) to bromide removal for minimizing bromate formation during ozonation. It was found that ion-exchange treatment affected ozone and hydroxyl radical concentration profiles as well as bromate ion concentration after ozonation. Selecting an appropriate ion exchanger is important to achieve both the oxidation of target contaminants and the reduction of bromate ion during ozonation.
\end{abstract}

Keywords

Ozonation; bromate ion; disinfection byproducts; bromide; ion exchange

\section{INTRODUCTION}

Ozonation is one of the key technologies in advanced drinking water treatment processes along with activated carbon treatment. Ozonation is known to be effective for controlling the precursors of chlorination byproducts (e.g., trihalomethanes), chlorine-resistant pathogenic organisms, and various micropollutants in drinking water treatment. In Japan, many water utilities have adopted ozonation for controlling offensive odor compounds (e.g., 2-MIB and geosmin) and trihalomethanes, a common class of disinfection by-products.

However, ozonation is not free from the problem of reaction byproducts. While the formation of chlorination byproducts is minimized by ozonation, several toxic chemicals unique to ozonation are produced. Among these compounds, bromate ion $\left(\mathrm{BrO}_{3}{ }^{-}\right)$has been a major concern in the past decades because of its high toxicity and stability in the treatment train (i.e., very difficult remove after formation). In many countries including Japan, bromate ion in drinking water is currently regulated at $10 \mu \mathrm{g} / \mathrm{L}$.

Considerable research efforts have been devoted to the minimization of bromate ion from ozonation and several methods have been proposed (Amy and Siddiqui, 1999). The most common approach is the optimization of ozone dose. In this approach, either ozone dose or aqueous ozone concentration is controlled to the lowest level for achieving the purpose of ozonation (e.g., decomposition of trihalomethanes precursors). Also, controlling $\mathrm{pH}$ is effective for controlling bromate ion formation. By reducing $\mathrm{pH}$, the formation of hydroxyl radical $(\bullet \mathrm{OH})$, one of the key oxidants for bromate formation, is limited.

While the above approaches are effective for reducing bromate ion concentration after ozonation, one should note that these methods sacrifice the oxidation capability of ozonation. This is true not only for the first approach (i.e., controlling ozone dose) but only for the $\mathrm{pH}$ control approach since this approach suppresses hydroxyl radical formation. Molecular ozone itself does not react with saturated compounds, and hydroxyl radical is the major oxidant for the decomposition of saturated compounds. Hence, the current strategies available for bromate ion control would not be sufficient for source waters with high ozone demand. 
One solution for the above problem to is bromide ion removal. In the past, several attempts have been made for bromide removal: membrane filtration (Amy and Siddiqui, 1999), adsorption by silver-doped aerogel (Sanchez-Polo et al., 2006), electrochemical oxidation of bromide to bromine $\left(\mathrm{Br}_{2}\right)$ (Kimbrough and Suffet, 2002), and ion exchange (Johnson and Singer, 2004). Among these technologies, ion exchange treatment appears to be the most promising option from a practical point of view because ion exchange is widely used in the field of water treatment engineering. However, it is still not clear how the pretreatment by ion exchangers affect to the chemistry of ozonation. That is, the effect of ion exchange treatment on ozone exposure (i.e., the CT value of molecular ozone) and hydroxyl radical exposure (i.e., the CT value of hydroxyl radical) is not fully understood.

The present study sheds the light on this problem. We investigated the impact of three different ion exchange treatments (two different ion exchange resins and one inorganic ion exchangers) on the parameters mentioned above. Also, we attempted to evaluate the effects of these ion exchange techniques based on bromate yield (i.e., bromate formation per ozone/hydroxyl radical exposures).

\section{MATERIALS AND METHODS}

\section{Materials}

All the chemical reagents used in this study were of reagent grade or better (mostly analytical grade), and were purchased from Wako pure chemical. All the aqueous solutions were prepared with ultra pure water treated by a Millipore Elix20 system.

Water sampled from Lake Biwa was used as the test solution after filtration by a $0.45 \mu \mathrm{m}$ membrane filter (Advantec). Also, before ion exchange treatment, $\mathrm{pH}$ and bromide ion concentration were adjusted to 7.0 and $100 \mu \mathrm{g} / \mathrm{L}$, respectively. The $\mathrm{pH}, \mathrm{DOC}$, and IC (inorganic carbon) before the adjustment were $7.4,4.2 \mathrm{mg} / \mathrm{L}$, and $9.2 \mathrm{mg} / \mathrm{L}$, respectively. Lake Biwa is the largest lake in Japan and serves as water source for more then 14 million people in the Kansai area in Japan.

Three ion exchangers were used in this study. Two of them were ion exchange resins: DIAION SA10A (SA10) manufactured by Mitsubishi Chemical and MIEX provided by Orica. The other one is an inorganic ion exchanger, a hydrotalcite compound (HTC). The HTC was synthesized by the hydrothermal method (Miyata, 1975; Reichle, 1986) from a metal cation solution. The ion composition of the cation solution was set to $\mathrm{Mg}^{2+}: \mathrm{Al}^{3+}: \mathrm{Fe}^{3+}=8: 1: 1 \mathrm{~mol} / \mathrm{mol} / \mathrm{mol}$ based on the previous study (Kuwahara et al., 2006).

The HTC crystallized and aged in a 1-L Teflon-lined hydrothermal reactor (TEM-D 1000M, Taiatsu Techno). The crystal structure of the HTCs was confirmed by XRD. Also, the metal composition of the HTC was determined to be $\mathrm{Mg}^{2+}: \mathrm{Al}^{3+}: \mathrm{Fe}^{3+}=0.783: 0.120: 0.197 \mathrm{~mol} / \mathrm{mol} / \mathrm{mol}$ by ICP-AES. This was sufficiently close to the intended the molar ratio of the cations.

\section{Procedure}

Ion exchange treatment was performed for 6 hours in batch mode. The doses of HTC, MIEX, and SA10 were set to $4 \mathrm{~g} / \mathrm{L}, 5 \mathrm{~mL} / \mathrm{L}$, and $2.5 \mathrm{~g} / \mathrm{L}$. These doses were selected to maintain their total ion exchange capacities approximately identical. They were determined based on a preliminary experiment in batch mode with excess concentrations of bromide and sulfate ions. After ion exchange, ion exchangers were removed from aqueous phase by a $1.0 \mu \mathrm{m}$ glass fiber membrane.

Ozonation was conducted in the batch mode (Figure 1). The ozone dose was fixed to $2.0 \mathrm{mg} / \mathrm{L}$. 
This dose is the roughly highest dose applied in Japan for drinking water treatment. Before ozonation, the stock solution of $p$-chlorobenzoic acid (pCBA, the probe compound of hydroxyl radical) was added. Ozonation experiments were started by injecting a small volume of ozone stock solution. The stock solution was prepared by bubbling ozone gas into ice-bathed cold water. With this method, we could assume 100\% ozone transfer into aqueous phase. During each run (usually 30-40 min), aqueous ozone and pCBA concentrations were monitored by taking the samples from the dispensing burette. This was necessary for calculating ozone and hydroxyl radical exposures.

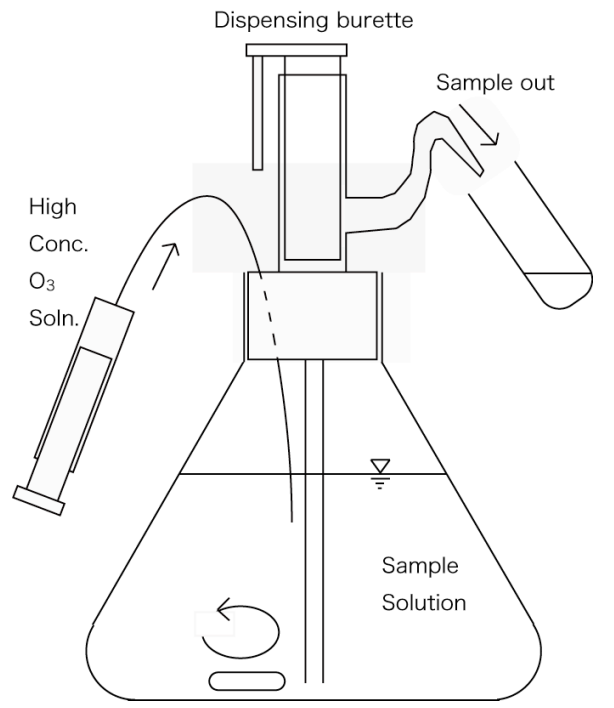

Figure 1. Schematic of the batch ozonation reactor.

\section{Analytical methods}

Bromide and other anion concentrations were determined by ion chromatography (LC-VP, Shimadzu) with a Shim-pack IC-A3 analytical column (Shimadzu) protected by a Shim-pack ICGA3 guard column (Shimadzu). The mobile phase was $50 \mathrm{mM}$ of boric acid/ $8 \mathrm{mM}$ of phydroxybenzoic acid/ $3.2 \mathrm{mM}$ bistris.

Concentration of pCBA was determined by reverse phase chromatography with an Inertsil PDS-3 column (GL Sciences Inc.) and a UV/Vis detector at $210 \mathrm{~nm}$. The mobile phase was $70 \%$ methanol.

DOC and IC were determined by a DOC analyzer (TOC-5000A, Shimadzu). Also, aqueous ozone concentration was determined by the indigo method.

\section{RESULTS AND DISCUSSION}

\section{Bromide ion and DOC removals}

Figures 2 and 3 show the bromide ion concentration and DOC after ion exchange treatment, respectively. The orders in bromide and DOC removals did not match. For example, HTC was the most effective for DOC removal, but the least effective for bromide removal. HTC appears preferential to organic ions than inorganic species. 


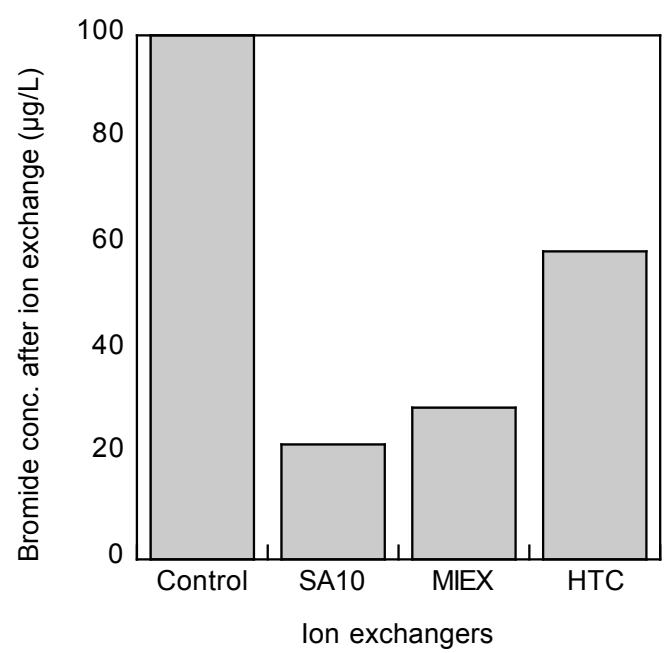

Figure 2. Bromide ion concentration after ion exchange.

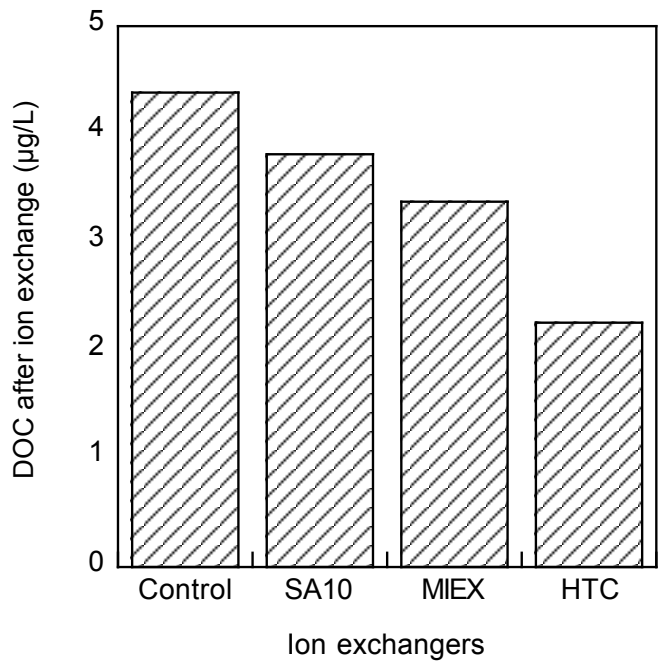

Figure 3. DOC after ion exchange treatment.

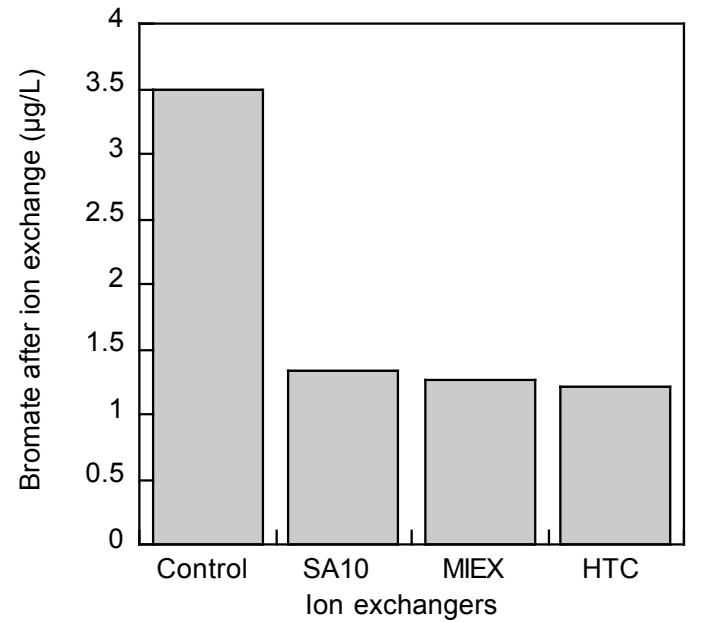

Figure 4. Bromate ion formation from ozonation after different ion exchange treatment at $\mathrm{pH} 7$ (ozone dose, $2.0 \mathrm{mg} / \mathrm{L}$ ). 


\section{Bromate ion formation}

Bromide removal by the three ion exchange treatments was effective for reducing bromate ion after ozonation (Figure 4). Approximately, 60\% reduction was possible for a same ozone dose. Also, while bromide ion removal percentage was considerably different, bromate ion concentrations after ozonation were similar when these ion exchange treatments were applied. This result implies that ion exchange treatment affect not only to bromide ion concentration but also other water quality parameters such as the type of DOM remaining after treatment.

\section{Ozone exposure}

In Figure 5, ozone exposures after the three ion exchange treatments were compared. Note that ozone exposure is the time integral of ozone concentration during the batch experiment until all the ozone was gone and determined by the following equation (Elovitz and von Gunten, 1999):

$\mathrm{O}_{3}$ exposure $=\int\left[\mathrm{O}_{3}\right] d t$

HTC treatment enhanced ozone exposure while ion exchange by the resins did not change ozone exposure significantly. This difference could be primarily attributed to the higher DOC removal by the HTC.

\section{Hydroxyl radical( $\bullet \mathrm{OH})$ exposure}

Figure 6 compares $\bullet \mathrm{OH}$ exposure during ozonation after ion exchange treatment. Similarly to ozone exposure, $\bullet \mathrm{OH}$ exposure, the time integral of $\bullet \mathrm{OH}$ concentration, was estimated with the equation below (von Gunten and Elovitz, 1999):

$\cdot \mathrm{OH}$ exposure $=\int[\cdot \mathrm{OH}] d t=-\left(\ln [\mathrm{pCBA}]_{\mathrm{e}} /[\mathrm{pCBA}]_{0}\right) / k$

where $[\mathrm{pCBA}]_{0}$ and $[\mathrm{pCBA}]_{\mathrm{e}}$ are the concentrations of pCBA before ozonation and after all the ozone was consumed, respectively, and $k$ is the second-order rate constant between $\bullet \mathrm{OH}$ and pCBA $\left(5 \times 10^{9} \mathrm{M}^{-1} \mathrm{~s}^{-1}\right.$ (von Gunten and Elovitz, 1999)). A second-order reaction was assumed between $\bullet \mathrm{OH}$ and pCBA following a previous work (von Gunten and Elovitz, 1999).

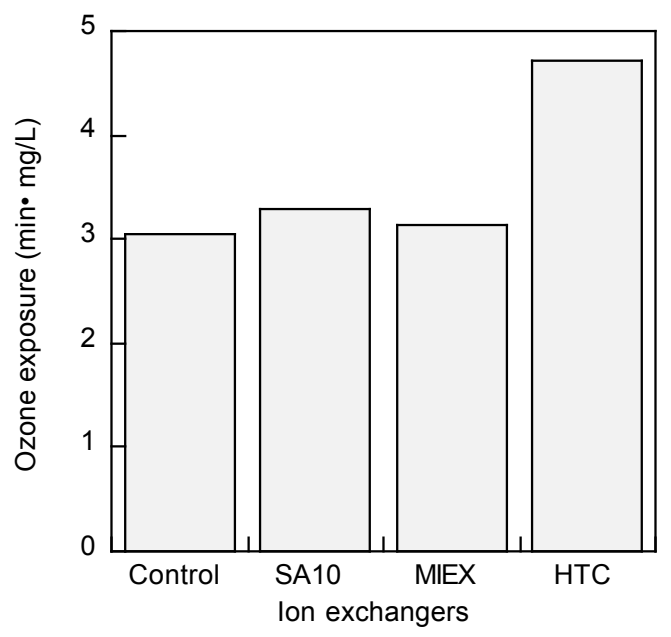

Figure 5. Ozone exposure during batch ozonation after different ion exchange treatments (Conditions: ozone dose, $2.0 \mathrm{mg} / \mathrm{L} ; \mathrm{pH}, 7.0$ ) 


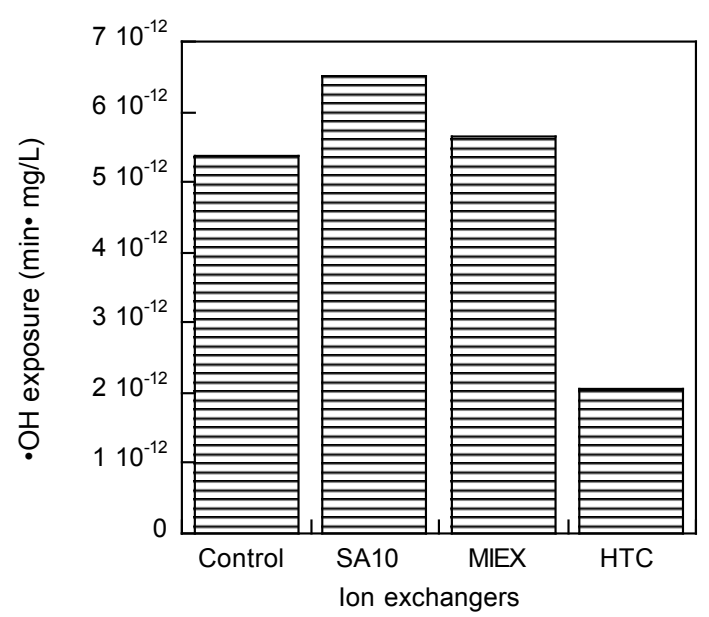

Figure 6. Hydroxyl radical $(\cdot \mathrm{OH})$ exposure during batch ozonation after different ion exchange treatments (Conditions: ozone dose, $2.0 \mathrm{mg} / \mathrm{L}$ ).

Once again, water treated by HTC behaved differently. That is, $\bullet \mathrm{OH}$ exposure suppressed to much greater extent than other ion exchange treatments. This result indicates that HTC treatment removed a DOC fraction related radial chain reaction of ozone decomposition (i.e., promoters of the radical chain reaction).

\section{Bromate ion formation per ozone exposure}

When the purpose of ozonation is oxidation of unsaturated organic compounds or disinfection, the bromate ion formation normalized by ozone exposure is an appropriate index of bromate formation (Note that we implicitly assumed that bromate ion formation was proportional to ozone exposure when other water quality parameters than ozone dose were fixed.).

In Figure 7, bromate yields per ozone exposures are compared. Clearly, HTC was the most effective when oxidation by molecular ozone was intended. Also, other ion exchange treatments were effective for the reduction of bromate yield per ozone exposure. In short, at least $60 \%$ reduction is expected by ion exchange treatment.

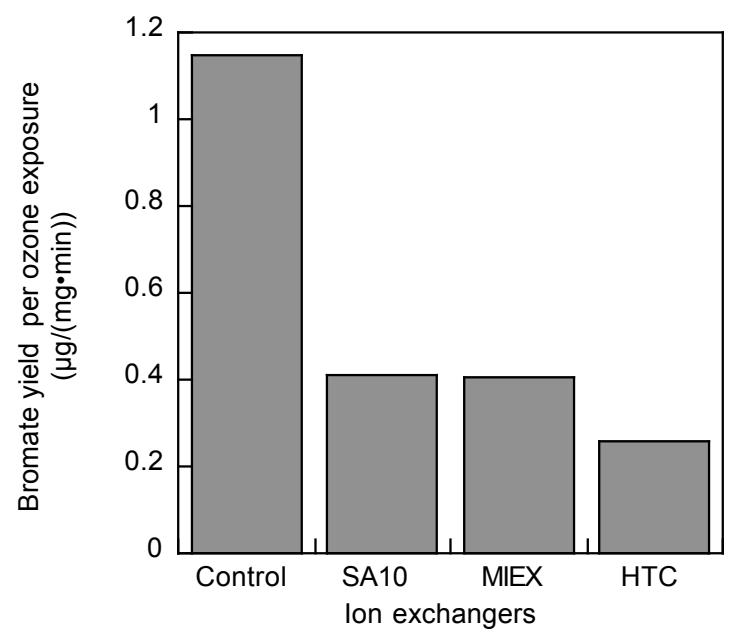

Figure 7. Bromate yield per ozone exposure. 


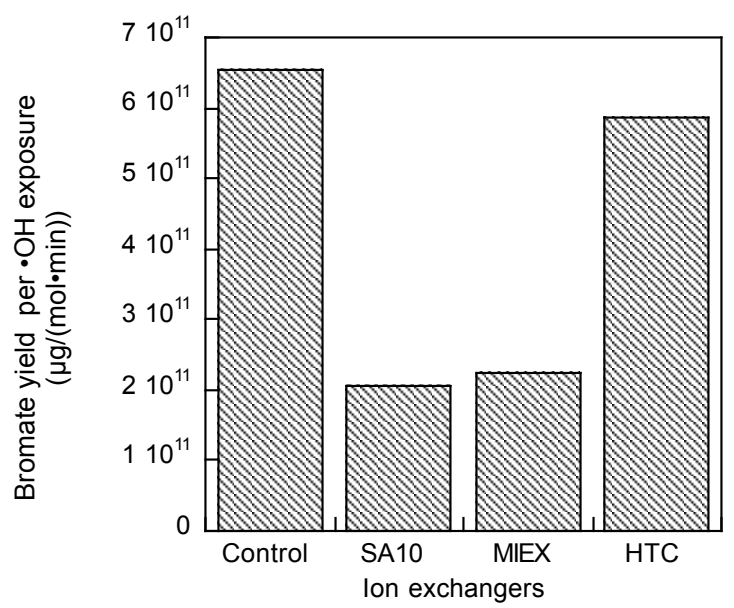

Figure 8. Bromate yield per hydroxyl radical exposure.

\section{Bromate ion formation per hydroxyl radial $(\bullet \mathrm{OH})$ exposure}

Similar analysis is possible using hydroxyl radical exposure. When the purpose of ozonation is oxidation of saturated organic compounds (e.g., decomposition of odor compounds), the bromate ion formation normalized by $\bullet \mathrm{OH}$ exposure is a more appropriate index of bromate formation than the bromate ion yield per ozone exposure. Note that in this evaluation we implicitly assumed that bromate ion formation was proportional to $\bullet \mathrm{OH}$ exposure when other water quality parameters than ozone dose were fixed. Actually, this assumption is identical to that in the evaluation using ozone exposure as $\bullet \mathrm{OH}$ exposure is approximately proportional to ozone exposure (Eloviz and von Gunten, 1999).

Contrary to the evaluation in the previous subsection, organic ion exchangers were better than HTC (Figure 8). This was mainly due to higher bromide removal by these ion exchangers. Bromide ion formation was reduced by $70 \%$ in these cases.

Together with the result in the previous subsection, it is concluded that the suitable ion exchanger for bromate minimization is different depending on the purpose of ozonation (i.e., depending on the chemical nature of the target compounds/organisms).

\section{Importance of removal of organic compounds for bromate ion minimization}

To highlight the effect of DOC removal on bromate ion formation, ozonation was performed with the water after ion exchange treatment followed by bromide ion adjustment to $100 \mu \mathrm{g} / \mathrm{L}$.

Surprisingly, we observed lower bromate ion concentration than control in all cases even with the bromide readjustment (data not shown). This result indicates that bromate reduction by ion exchange treatment is not only caused by the reduction of bromide ion but also by the change in DOC content. Therefore, it is very important to pay close attention to the DOC characteristics before and after ion exchange treatment even when the byproduct of concern is an inorganic compound (in this case bromate ion).

\section{CONCLUSIONS}

In this study, we applied several different ion exchangers (i.e., anion exchange resins and a 
hydrotalcite compound) to bromide removal for minimizing bromate formation during ozonation. It was found that ion-exchange treatment affected ozone and hydroxyl radical concentration profiles as well as bromate ion concentration after ozonation. Selecting an appropriate ion exchanger is important to achieve both the oxidation of target contaminants and the minimization of bromate ion during ozonation. Also, it was implied that the change in DOC content by ion exchange treatment had significant impact on the performance of ozonation and bromate ion formation.

\section{REFERENCES}

Amy, G.L. and Siddiqui, M.S. (1999). Strategies to Control Bromate and Bromide, American Water Works Association Research Foundation Final Project Report, Denver, USA .

Elovitz, M.S. and von Gunten, U. (1999). Hydroxyl radical ozone ratios during ozonation processes. I-The $R$-ct concept, Ozone: Sci. Eng., 21(3), 239- 260.

Johnson, C.J. and Singer P.C. (2004). Impact of a magnetic ion exchange resin on ozone demand and bromate formation during drinking water treatment, Water Res., 38, 3738-3750.

Kimbrough, D.E. and Suffet I.H. (2002). Electrochemical removal of bromide and reduction of THM formation potential in drinking water, Water Res., 36, 4902-4906.

Kuwahara, M. (2006). Selective bromide removal by ion exchange processes, Master Thesis, Department of Urban Management, Graduate School of Engineering, Kyoto University.

Miyata, S. (1975). The synthesis of hydrotalcite-like compounds and their physico-chemical properties -I: the systems $\mathrm{Mg}^{2+}-\mathrm{Al}^{3+}-\mathrm{NO}_{3}^{-}, \mathrm{Mg}^{2+}-\mathrm{Al}^{3+}-\mathrm{Cl}^{-}, \mathrm{Mg}^{2+}-\mathrm{Al}^{3+}-\mathrm{ClO}_{4}^{-}, \mathrm{Ni}^{2+}-\mathrm{Al}^{3+}-\mathrm{Cl}^{-}$and $\mathrm{Zn}^{2+}-\mathrm{Al}^{3+}-\mathrm{Cl}$, Clays Clay Miner., 23, 369-375.

Reichle, W.T., (1986). Synthesis of anionic clay minerals (mixed metal hydroxides, hydrotalcite), Solid States Ionics, 22, 135-141.

Sanchez-Polo M., Rivera-Utrilla J. and von Gunten, U. (2006). Bromide and iodide removal from waters under dynamic conditions by Ag-doped aerogels, J. Colloid Interface Sci., 306, 183-186. 